www.jmscr.igmpublication.org Impact Factor 5.244

Index Copernicus Value: 5.88 ISSN (e)-2347-176x ISSN (p) 2455-0450 crossref DOI: _http://dx.doi.org/10.18535/jmscr/v4i6.19

\title{
Thyroid Hemiagenesis with Agenesis of Isthmus a Case Report
}

\section{Authors \\ Dr Berjina Farooq Naqshi ${ }^{1}$, Dr Sulaiman Seth ${ }^{2}$, Dr Adil Bashir Shah ${ }^{2}$, Dr Sangeeta Gupta ${ }^{3}$, Dr Sunanda Raina ${ }^{4}$}

${ }^{1}$ pg scholar Department of Anatomy GMC Jammu, ${ }^{2} \mathrm{MS}$ orthopaedics GMC Srinagar, ${ }^{3}$ Professor Department of Anatomy GMC Jammu, ${ }^{4}$ Professor and head Department of Anatomy GMC Jammu,

Corresponding Author

Dr Adil Bashir Shah

Email: adilshah111@gmail.com

\begin{abstract}
Thyroid gland is an endocrine gland being highly vascular, having two lobes which are connected by an isthmus. Gland is somewhat H shaped in appearance. Thyroid anomalies can be in the form of unilateral lobar agenesis. In this case report, right lobe of the thyroid gland is absent along with the isthmus. The significance lies in the fact that surgeons ought to know about various anomalies of the gland to plan a safe surgery.
\end{abstract}

Keywords: Isthmus, thyroid, agenesis

\section{INTRODUCTION}

Thyroid is brownish red gland which extends from C5 to T1 vertebra. ${ }^{1}$ Thyroid is the primary endocrine gland to start development in embryo. ${ }^{2}$ Thyroid agenesis was reported by Marshall ${ }^{3}$ in 1895 who noticed one child with right lobe absent among 60 childhood thyroid glands. Patients having thyroid hemiagenesis are supposed to have accompanying thyroid disorders. The prevalence of thyroid hemiagenesis is $0.02 \%$ in normal children, a rough estimation ${ }^{4}$.Females are more common candidates for thyroid agenesis and the lobe usually absent in them is the left one ${ }^{5}$.Left lobe hemiagenesis was detected by Das in $1962{ }^{6}$.

\section{CASE REPORT}

During the routine dissection work in the Department of Anatomy, Government Medical College, Jammu, the thyroid gland in the male cadaver presented with absence of right lobe of thyroid gland along with the isthmus, with normal left lobe. The left lobe was measuring $6.9 \mathrm{~cm}$ in length and $3.7 \mathrm{~cm}$ in width. The direction of the apex of the left lobe is towards the oblique line on thyroid cartilage and external laryngeal nerve and superior thyroid artery lies in its vicinity, the base is in relation with right laryngeal nerve and inferior thyroid artery. The thyroid gland was placed in its proper anatomical position except for the absence of its right lobe and isthmus was absent from its proper anatomical position in front of 2 nd and $3^{\text {rd }}$ tracheal cartilage. Left lobe was supplied by superior and inferior thyroid artery. 


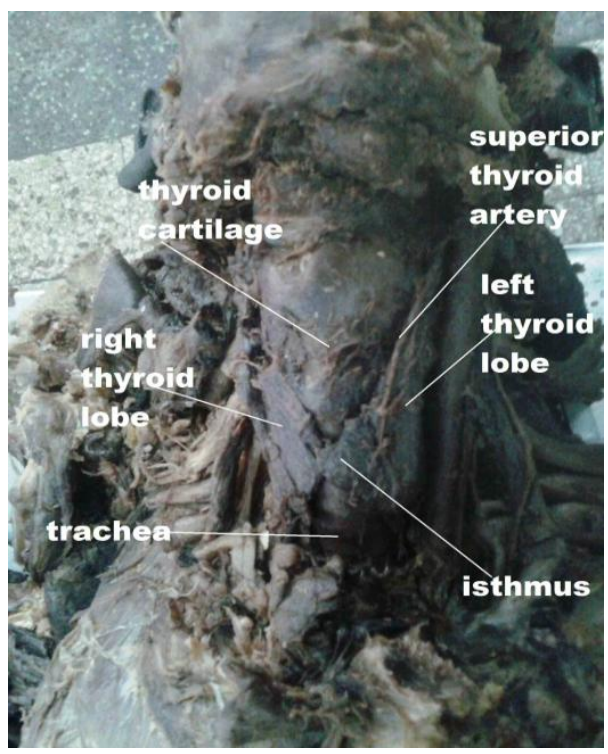

Fig 1.Normal thyroid anatomy

\section{DISCUSSION}

Literature regarding thyroid agenesis is rich as per its variations are concerned. Agenesis of thyroid gland being rare congenital anomaly presents with absence of a lobe of thyroid gland or lobe and isthmus or both. Its development begins from the foramen caecum in the midline ${ }^{7}$. The gland makes its appearance in the floor of pharynx as an epithelial proliferation which later is indicated by foramen caecum. It makes its descent as bilobed diverticulum in front of pharyngeal gut. During its descent, the gland maintains a connectivity, with the tongue by means of a duct known as thyroglossal duct, which then disappears later ${ }^{8}$.Thereafter it further moves downwards in front of hyoid bone and cartilages of the larynx. By $7^{\text {th }}$ week, it reaches in front of trachea which is its final destination. By that time, it has acquired shape of bilobed structure with an intervening isthmus. Hemiagenesis is thought to result from impaired migration process or any malfunctioning during process of lobulation either because of genetic or environmental elements. Role of chromosome 22 have been cited by some authors as cause of thyroid lobe agenesis.

Hemiagenesis of gland, ranged between $0.005 \%$ and $0.2 \%$ and its prevalence is more in females ${ }^{9,10 .}$ Gursoy et al. ${ }^{9}$ found in their study the prevalence of hemiagenesis to be $0.25 \%$ in patients having thyroid disorders whereas the normal population

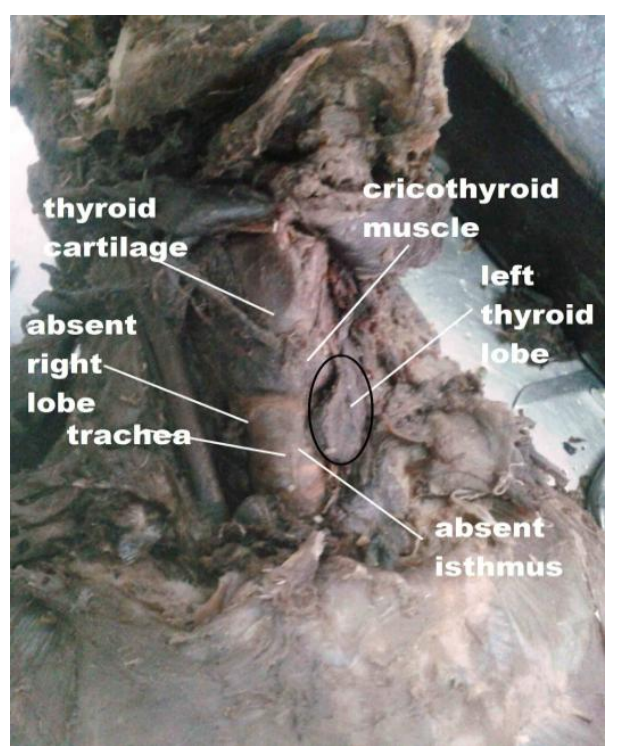

Fig 2. Agenesis of right thyroid lobe and isthmus

had a prevalence of $0.025 \%$ and the absence of left lobe was seen in all cases but in our case there is absence of right lobe and isthmus. The absence of isthmus was claimed to be rare in humans by various workers ${ }^{11}$.

Won and Chung concluded that the isthmus was absent in $3 \%$ of the cases studied by them ${ }^{12}$ .Braun et al. researched on 58 cadavers and conveyed that isthmus was absent in 4 cadavers ${ }^{13}$.Pastor et al. said that the absence of isthmus is accompanied either by the absence of a lobe or the presence of ectopic thyroid ${ }^{14}$.Ranade et al. conveyed the $33 \%$ incidence of absence of isthmus. ${ }^{15}$ In this case report we have absence of right lobe of thyroid gland accompanied by the absence of isthmus.

The most common dysorganogenesis is absence of isthmus followed by hemiagesis ${ }^{16}$. The hemiagenesis of thyroid gland is more prevalent in symptomatic patients than normal people ${ }^{8}$.Agenesis of thyroid gland can be diagnosed by ultrasonography ,CT scan ,MRI but its diagnoses is usually difficult unless the patients refer for other thyroid ailments. ${ }^{17}$

The clinical significance of this case is that the individual diagnosed with absence of isthmus should be screened for cancers of thyroid, metastasis, amyloidosis, thyroiditis etc. Malignancy always remains a cause for concern. ${ }^{18}$ 


\section{CONCLUSION}

Thyroid agenesis is a rarity that being asymptomatic can't be diagnosed easily unless the patient comes for another condition. Its diagnosis is usually incidental. Its awareness can help surgeons in proper surgeries. Undue interventions can be avoided in patients. Moreover our study helps to better understand the anatomy of thyroid gland.

\section{BIBLIOGRAPHY}

1. Dixit D, Shilpa MB, Harsh MP and Ravishankar MV. Agenesis of isthmus of thyroid gland in adult human cadavers: A case series .Cases Journal 2009; 2 :6640

2. Khaladkar SM, Garg S, Sherawat P and Kamal A. Thyroid Hemiagenesis with isthmic agenesis: A case report with review of the literature. Med J DY Patil Univ.2015; 8: 559-62

3. Marshall CF. Variations in the form of the thyroid gland in man. $\mathbf{J}$ Ana Physiol 1895;29: 234-39

4. Maiorana R, Carta A , Floriddia G, Leonardi D, Buscema M, Sava L, et al. Thyroid Hemiagenesis: Prevalence in normal children and effect on thyroid function . J. Clin Endocrinol Metab.2003;88(4):1534-36

5. Mikosch P, Gallowitsch HJ, Kresnik E, Molnar M, Gomez I and Lind P. Thyroid hemiagenesis in an endemic goiter area diagnosed by ultrasonography: Report of sixteen patients. Thyroid 1999;9(11):107584.

6. Das P. Congenital absence of one thyroid lobe. J. Ind Med Assoc. 1962; 39:302-04.

7. Kaplaw EL, Shukla M, Hara H and Ito K. Developmental abnormalities of the thyroid In: De Groot LJ(Ed) Endocrinology. Philadelphia Saunders 1994;893-99

8. Sadler TW. Head \& neck . Langman's Med Embryol 2006;1 0:270
9. Gursoy A, Anil C, Unal AD, Demirer AN, Tutuncu NB and Erdogan MF. Clinical and epidemiological characteristics of thyroid hemiagenesis: Ultrasound screening in patients with thyroid disease \& normal population. Endocrine 2008 ; 33(3): 338-41.

10. Pena S, Robertson $H$ and Walvekar RR. Thyroid hemiagenesis: Report of a case and review of literature. Indian J.otolaryngol Head Neck Surg 2011; 63(2):198-200

11. Romanes GJ. Cunningham's Textbook of Anatomy $\left(12^{\text {th }}\right.$ ed) Oxford: Oxford University Press, 1981;57-59,286,596-97

12. Won HS and Chung IH. Morphological variations of the thyroid gland in the Korean adults. Korean J Phys Antropol 2002;15:119-25

13. Braun E, Windisch G, Wolf G, Hausleitner $\mathrm{L}$ and Anderhuber F. The pyramidal lobe:Clinical anatomy \& its importance in thyroid surgery.Surg Radiol Anat 2007;29:21-27

14. Pastor VJF, Gil VJA, De Paz Fernandez FJ and Cachorro MB. Agenesis of thyroid isthmus. Eur J Anat 2006;10:83-84

15. Ranade AV, Rai R, Pai MM, Nayak SR, Prakash Krishnamurty A and Narayana S. Anatomical variation of the thyroid gland :possible surgical implications. Singapore Med J 2008 ;49:831-34

16. Korpal-Szczyrska M, Kosiak W and Swieton D. Prevalence of thyroid hemiagenesis in an asymptomatic school children population.Thyroid.2008;18(6): 637-39

17. Vishwanath TT, Singh S, Shetty SM and Apoorva C. Thyroid hemiagenesis presenting as hypothyroidism- A rare case report .Nepal J Radiol 2013;3:77-79

18. Tiwari PK, Baxi M, Baxi J and Koirala D. Right handed hemiagenesis of the thyroid lobe \& isthmus. A case report .Indian $\mathrm{J}$ Radiol Imaging 2008;18(4): 313-15 